\title{
FORMAÇÃO DE PROFESSORES PARA A EDUCAÇÃO BILÍNGUE DE SURDOS NA EDUCAÇÃO INFANTIL E SÉRIES INICIAIS DO ENSINO FUNDAMENTAL ${ }^{1}$
}

\author{
FORMACIÓN DE DOCENTES PARA LA EDUCACIÓN BILÍNGUE DE SURDOS \\ EN LA EDUCACIÓN INFANTIL Y SERIES INICIALES DE LA ENSEÑANZA \\ FUNDAMENTAL
}
TEACHER TRAINING FOR BILINGUAL EDUCATION OF DEAF IN CHILD EDUCATION AND INITIAL SERIES OF FUNDAMENTAL EDUCATION

\author{
Joice Emanuele Munhoz CICILINO2 \\ Claudia Regina Mosca GIROTO ${ }^{3}$
}

Fabiana Cristina Frigieri de VITTA ${ }^{4}$

RESUMO: Este estudo objetivou analisar como a formação de professores para atuação na educação bilíngue de surdos na educação infantil e séries iniciais do ensino fundamental tem sido retratada nas produções de fontes reconhecidamente relevantes no cenário acadêmico-científico brasileiro, entre os anos 2005 e 2015, período relacionado a designações do Decreto $n^{\circ} 5.626 / 2005$. Conclui-se que, embora os estudos sobre a formação de professores para atuação na educação bilíngue de surdos tenham contribuído com importantes reflexões, a temática ainda é pouco explorada na literatura científica. Pouco se avançou no cenário brasileiro, a respeito da formação específica de professores para atuação com alunos surdos na perspectiva bilíngue, assim como na implantação de modelos educacionais bilíngues para esses alunos.

PALAVRAS-CHAVE: Formação de professores. Educação Bilíngue. Surdo.

RESUMEN: Ese estudio tuvo como objetivo analizar cómo la formación de los docentes para actuar en educación bilingüe de sordos en la educación infantil temprana y en los grados de la escuela primaria han sido retratada en las producciones de fuentes conocidas como relevantes en el escenario Brasileño académico-científico, entre los años 2005 y 2015, período relacionado con las designaciones del Decreto No.

\footnotetext{
${ }^{1}$ Os dados aqui considerados encontram-se vinculados ao Projeto CNPq Processo $\mathrm{n}^{\circ}$ 406241/2016-3, ao qual as autoras se encontram vinculadas.

${ }^{1}$ Universidade Estadual Paulista (UNESP), Araraquara - SP - Brasil. Mestre pelo PPGEE/FCLAr. ORCID <https://orcid.org/0000-0001-8543-864X>. E-mail: joice.cicilino@gmail.com

3 Universidade Estadual Paulista (UNESP), Marília - SP - Brasil. Docente do Programa de PósGraduação em Educação (PPGE) e do Departamento de Educação Especial, Faculdade de Filosofia e Ciências (FFC), Campus de Marília/SP e do Programa de Pós-Graduação em Educação Escolar (PPGEE), Faculdade de Ciências e Letras (FCLAr), Campus de Araraquara/SP. Doutora em Educação. ORCID <https://orcid.org/0000-0001-6267-8085>.E-mail: claudia.mosca@unesp.br

${ }^{4}$ Universidade Estadual Paulista (UNESP), Marília - SP - Brasil. Docente do Departamento de Educação Especial, Faculdade de Filosofia e Ciências (FFC), Campus de Marília/SP e do Programa de PósGraduação em Educação Escolar (PPGEE), Faculdade de Ciências e Letras (FCLAr), Campus de Araraquara/SP. Doutora em Educação Especial. ORCID <http://orcid.org/0000-0001-9545-7588>. Email: fabiana.vitta@unesp.br
}

RPGE- Revista on line de Política e Gestão Educacional, Araraquara, v. 22, n. esp. 2, p. 794-809, dez., 2018. ISSN: 1519-9029. DOI: 10.22633/rpge.unesp.v22.nesp2.dez.2018.11913 
5.626/2005. se concluye que, aún que los estudios sobre la formación de los docentes para actuar en la educación bilingüe de los sordos han contribuido con reflexiones importantes, el tema sigue siendo pobremente explorado en la literatura científica. Poco ha progresado en el escenario brasileño, con respecto a la formación específica de los docentes para trabajar con estudiantes sordos en la perspectiva bilingüe, así como en la implementación de modelos educativos bilingües para estos estudiantes.

PALABRAS CLAVE: Formación de docentes. Educación bilingüe. Sordo.

ABSTRACT: This theoretical work implied to analyze how the teacher training in the bilingual education of the deaf in early childhood education and initial grades of elementary education have been represented in the productions of relevant sources in the Brazilian academic and scientific scenario between 2005 and 2015, a period related to the designations of Decree no. 5626 / 2005. The conclusion is that, although studies on teacher training for bilingual education of the deaf have contributed important reflections, the subject is not sufficiently explored in the scientific literature. Little headway has been made in the Brazilian scenario, regarding the teacher training to work with deaf students in the bilingual perspective, as well as in the implantation of bilingual educational models for these students.

KEYWORDS: Teacher training. Bilingual Education. Deaf.

\section{Introdução}

Os embates e argumentos em defesa das escolas bilíngues para surdos, com a recente criação de cursos de pedagogia bilíngue para a formação de professores, têm se constituído em importante questão no cenário educacional atual. Sob a abordagem educacional bilíngue é proposto o acesso do surdo a duas línguas: a língua brasileira de sinais (Libras), como língua de instrução, e a oficial do país, como segunda língua que, no contexto brasileiro, diz respeito à apropriação do português escrito.

A Libras foi reconhecida e oficializada como língua natural dos surdos através da Lei n. ${ }^{\circ} 10.436 / 2002$ (BRASIL, 2002), posteriormente regulamentada pelo Decreto $\mathrm{n}^{\mathrm{o}}$ 5.626/2005 (BRASIL, 2005). Apresenta “[...] uma estrutura gramatical tão rica e complexa quanto à de qualquer língua oral. Por apresentar uma organização estrutural decorrente de sua modalidade gestual-visual-espacial" (FERNANDES, p. 42, 2003).

Sob esse ponto de vista, a Libras recebe o status de língua, implicando na compreensão de que, como língua de instrução, possibilitará ao surdo, em seu processo de escolarização, a garantia de condições materiais e subjetivas para a apropriação dos conhecimentos veiculados na e pela escola e, consequentemente, para o acesso ao currículo, à educação de melhor qualidade e aos bens culturais socialmente valorizados. 
Tal reconhecimento pressupõe a desconstrução da compreensão reducionista e equivocada acerca das Libras como mero recurso comunicacional e/ou pedagógico. Da condição de língua, a Libras é fundamental, então, para a instauração de situações dialógicas e, consequentemente, de práticas sociais que possibilitarão a constituição do sujeito surdo (GIROTO; BERBERIAN; SANTANA, 2014).

Para que o aluno surdo conclua a modalidade da educação básica em condição de igualdade com o aluno ouvinte, frente a esses objetivos, é possível presumir que a Libras precisaria ser assumida, portanto, na perspectiva bilíngue, desde a educação infantil, como primeira língua e como língua de instrução, além do aprendizado do português escrito. Nesse sentido, o Decreto $n^{\circ}$ 5.626/2005 (BRASIL, 2005), em seu artigo Art. 22, incisos I e II, previu a educação bilíngue. Embora esse dispositivo legal recomende a organização da educação de surdos sob essa abordagem, desde 2005, com prazo para sua sistematização até 2015 , como parte de um conjunto de determinações legais contidas nesse documento, a exemplo da escola bilíngue e da classe bilíngue no ensino regular para a educação infantil e séries iniciais do ensino fundamental, decorrida mais de uma década, não foram sistematizadas como possibilidades educacionais para esse alunado.

Entendemos que parte dessa problemática encontra-se atrelada ao fato de que esse decreto não trata sobre as especificidades da formação de professor bilíngue de surdos e ouvintes na educação infantil e séries iniciais do ensino fundamental, oferecida em cursos superiores de Pedagogia Bilíngue Libras/Português, bem como não apresenta critérios para a elaboração de propostas pedagógicas e matrizes curriculares que garantam que, nessa formação inicial, o professor terá se apropriado de conhecimentos suficientes de e sobre as Libras, ainda que recomende a oferta de disciplina de Libras na formação de pedagogos, demais licenciaturas e cursos de fonoaudiologia. Tendo decorrido mais de uma década desde a promulgação desse dispositivo legal e considerando que o ano de 2018 marca uma década da Política de Educação Especial na Perspectiva da Educação Inclusiva (BRASIL, 2008), a reflexão sobre as condições de formação do professor para atuação na educação bilíngue de surdos e acerca do lócus dessa formação assume relevância diante do atual contexto educacional atual.

Frente a esse cenário, esse estudo objetivou mapear e analisar o estado da arte sobre a formação do professor para atuação na educação bilíngue de surdos na educação infantil e séries iniciais do ensino fundamental I, no período decorrido entre 2005, ano 
da promulgação do Decreto $n^{\circ}$ 5.626/2005 (BRASIL, 2005), a 2015, prazo final para a implantação das recomendações contidas nesse documento.

\section{Percurso metodológico}

O delineamento proposto, sob um enfoque qualitativo, compreendeu uma revisão bibliográfica sistemática de natureza descritivo-interpretativa. Para tal, foram consideradas as bases de dados: Scientific Eletronic Library Online (SciELO) e as bibliotecas digitais da Universidade de São Paulo (USP), da Universidade Estadual de Campinas (Unicamp) e da Universidade Estadual Paulista (Unesp). Para tal mapeamento foram considerados os descritores: "bilíngue"; "educação bilíngue"; "surdo"; "formação de professores"; "políticas de formação de professores"; e "pedagogia bilíngue".

Para a análise empreendida, o conjunto de publicações permitiu a elaboração dos eixos de análise: "Formação de professores para atuação com surdos", "Educação Bilíngue na constituição do aluno surdo" e "Repercussões da educação bilíngue no âmbito das políticas públicas educacionais".

\section{Resultados e discussão}

Os dados apresentados indicaram um total de 32 publicações sobre a temática investigada, sendo dois artigos e um Trabalho de Conclusão de Curso (TCC) no ano de 2006; um TCC em 2008; um artigo, um TCC e uma dissertação de mestrado em 2009; um artigo em 2010 e um artigo em 2011; um artigo e uma dissertação de mestrado em 2012; dois artigos, um TCC e uma dissertação de mestrado em 2013; sete artigos, um TCC e um relatório em 2014 e três artigos, quatro TCC e uma dissertação de mestrado em 2015. No ano de 2005 e 2007 nenhuma publicação foi encontrada sobre o tema nas fontes pesquisadas.

A seguir são apresentados os eixos elencados com base nas produções científicas identificadas no período de 2005 a 2015, a partir dos tipos de publicações.

O eixo "Formação de professores para atuação com surdos" compreendeu seis publicações, sendo dois artigos, uma tese de doutorado, uma dissertação de mestrado e dois TCC. 
Quanto aos artigos mencionados, Franco (2009) publicou sobre a experiência de ensino superior bilíngue no INES/Instituto Superior Bilíngue de Educação (ISBE), com o curso de Pedagogia e os principais entraves a sua implantação. Ressaltou que há muito a fazer: traçar novos planos e buscar corrigir falhas que possam comprometer o compromisso firmado na luta por uma melhoria nas condições de oferta do ensino de surdos no Brasil, em todos os níveis. Por sua vez, Faria (2011) objetivou, em seu artigo, compreender o significado da denominação Instrutor de Libras e Professor de Libras dentro da escola e de que maneira essa denominação encontra-se expressa no referido decreto. Verificou que Instrutor de Libras tem sido a denominação atribuída ao profissional surdo, mesmo quando ele exerce atividade peculiar à docência e possui formação pedagógica. Concluiu que o profissional surdo é essencial para garantir uma educação de qualidade ao sujeito com surdez e é dever do poder público contribuir para a sua formação.

Em sua tese de doutorado, Soares (2013) realizou uma pesquisa com aprofundamento bibliográfico dos principais desafios na formação inicial de professores para atuar na educação básica com alunos surdos no contexto da educação bilíngue. Concluiu que, além da inserção da disciplina Libras, não foram localizadas produções que informem sobre ações abrangentes que as IES estejam promovendo para formar professores que atenderão aos alunos surdos na educação bilíngue.

Souza (2012), em sua dissertação de mestrado, discutiu a formação do professor bilíngue apresentando histórias, experiências e fatos vividos no período em que foi estudante de Pedagogia, apresentando sua experiência em um projeto de inclusão bilíngue no Município de Campinas. Concluiu que, para atuar com alunos surdos, é necessária uma profunda mudança na grade curricular dos cursos de formação de professores.

Quanto aos TCC relacionados nesse eixo, Portioli (2006) verificou sob quais condições se deu a inclusão de uma aluna surda no ensino regular de Campinas. Revelou alguns equívocos encontrados na formação dos professores e concluiu que os cursos de formação de professores não têm preparado os mesmos para as exigências impostas pela política de inclusão, ou seja, não há uma real mudança na prática de inclusão. Por sua vez, Silva (2015) buscou, em seu TCC, entender alguns dos fatores que dificultam ou até impedem que os indivíduos surdos tenham acesso ao ensino superior, em Universidades da cidade de Campinas, com foco nos cursos de Pedagogia e Licenciaturas, e dentro deste quadro analisou a estrutura dos currículos de formação 
de professores para a Educação Básica. A autora constatou que os currículos estão longe de dar ao professor as condições propícias para sua atuação efetiva com as especificidades desses alunos.

É interessante observar nas produções identificadas nesse eixo, a concordância dos autores quanto aos diversos desafios à formação do professor para atuar com alunos surdos. Os autores revelam que a atual formação oferecida não prepara o professor para as exigências impostas pela inclusão. Nesse sentido, Giroto, Martins e Lima (2015) denotam que a escola pouco tem se organizado para atender as singularidades linguísticas, culturais e cognitivas dos surdos no sistema regular de ensino. A esse respeito, acenam que as crianças e jovens surdos se sentem prejudicados pela baixa efetividade do sistema educacional no que se refere à garantia da aprendizagem, aliada à ineficiência da formação docente.

Um aspecto relevante trazido no trabalho de Souza (2012) merece destaque, a divergência existente da hora/aula da disciplina de Libras comparada com as demais. Giroto, Martins e Lima (2015), ao investigarem a inserção da disciplina Libras em cursos de pedagogia de uma universidade pública estadual alertaram para a necessidade de discussão mais aprofundada sobre o papel dessa disciplina na formação de professores.

A inserção da Libras nos cursos de Pedagogia não pode ser a única alternativa para o desenvolvimento acadêmico de surdos. Há que se pensar em propostas diferenciadas para atender as demandas educacionais desse público (GIROTO; PINHO; MARTINS, 2016).

Muitos são os desafios, como ressaltam Portioli (2006), Franco (2009), Soares (2013) e Silva (2015). As políticas educacionais vigentes (BRASIL, 2002; 2005), embora tenham representado um avanço em relação à educação de surdos na perspectiva bilíngue, de fato não alcançaram, ainda, efetividade no sistema educacional, tendo em vista a predominância da estrutura educacional que prevê a frequência desses alunos em classes comuns do ensino regular, e em salas de recursos multifuncionais (SRM) para oferta de atendimento educacional especializado (AEE), no contraturno, a partir da promulgação da Política Nacional de Educação Especial na Perspectiva da Educação Inclusiva (PNEEPEI) (BRASIL, 2008).

No eixo "Educação bilíngue na constituição do sujeito surdo" foram consideradas 18 publicações, sendo 12 artigos, uma dissertação de mestrado e cinco TCC. 
Tal eixo contemplou, dentre os artigos relacionados, a publicação de Guarinello (2006), que constatou a problemática que envolve a inclusão do surdo no ensino regular, a partir da visão de um grupo de professores. A análise evidenciou que os professores não relacionaram suas dificuldades para ensinar com as dificuldades de seus alunos para aprender, como se o desconhecimento dos professores acerca da surdez, por exemplo, não tivesse implicações diretas na aprendizagem dos surdos, bem como consideraram que a presença do intérprete em sala de aula seria, de certa forma, o aspecto mais importante capaz de promover aos alunos surdos uma aprendizagem efetiva.

Peixoto (2006) propôs, em seu artigo, uma reflexão psicolinguística sobre as construções conceituais de crianças surdas no que diz respeito à escrita. $\mathrm{O}$ artigo revelou que a psicogênese da escrita vivenciada por crianças surdas se desenrola de forma diferente ao que é vivido por crianças ouvintes em processo inicial de construção da escrita. Concluiu que a escola e o professor alfabetizador devem rever suas concepções sobre o processo de escrita do surdo.

Angelucci e Luz (2010) discutiram, em seu artigo, as contribuições da escola para a constituição da identidade de sujeitos surdos. Concluíram que, no caso da população surda, pode não haver consenso a respeito dos efeitos da escolarização em instituições inclusivas ou especializadas, mas sobre um aspecto não há controvérsia: os profissionais da Educação, onde quer que trabalhem, precisam de liberdade para criar e recriar os espaços e as estratégias de aprendizagem.

Eyng (2012) apresentou em seu artigo a prática de inclusão de surdos matriculados no ensino regular do município de Medianeira/PR, sob a percepção de professores, intérpretes, familiares e alunos surdos, além de apontar sugestões desses grupos para a melhoria desse processo. Os resultados da pesquisa demonstraram contradições entre a proposta de inclusão escolar de surdos e a prática realizada nas escolas, porém, para os familiares e alunos surdos a inclusão está acontecendo.

Marques, Barroco e Silva (2013) teceram considerações teóricas em seu artigo a respeito do ensino da Libras na educação infantil como recurso na mediação entre crianças ouvintes e surdas e discutiram seu impacto sobre o desenvolvimento humano. Concluíram que o ensino de Libras pode favorecer a aprendizagem e o desenvolvimento de crianças surdas e ouvintes, permitindo, sobretudo, a multiplicação do número de interlocutores.

Streiechen e Krause-Lemke (2014) discutiram a elaboração da escrita de alunos surdos que passaram por um processo de alfabetização com proposta bilíngue. As 
autoras, dentre as conclusões às quais chegaram, destacaram que a criança surda só iniciará seu aprendizado de uma língua escrita após dominar a língua de sinais e que o aluno surdo não estará necessariamente alfabetizado se apenas copiar do quadro ou dos colegas e não associar o que escreve com o seu significado.

Quadros, Lillo-Martin e Pichler (2014) analisaram produções espontâneas de crianças bilíngues bimodais que são sensíveis às línguas e seus interlocutores, enquanto apresentam uma influência considerável da língua dominante da sua comunidade. Os autores concluíram que, de modo geral, os resultados encontrados indicaram uma influência considerável dessa língua dominante.

Lodi, Bortolotti e Cavalmoreto (2014) discutiram, a partir de pressupostos bakhtinianos, algumas especificidades das práticas de letramento de surdos. As autoras apresentaram uma proposta educacional na qual os alunos, a partir da vivência da Libras em sua dimensão discursiva/genérica, têm desenvolvido práticas de letramento nas duas línguas.

Nascimento e Costa (2014) descreveram a trajetória percorrida pela comunidade surda de Brasília para a implantação da primeira escola pública integral bilíngue Libras e português escrito do Distrito Federal, bem como reafirmaram os benefícios que as escolas bilíngues oferecem para os surdos e para os ouvintes.

Silva e Bolsanello (2014) identificaram, em seu artigo, distintas proposições metodológicas de ensino da escrita para surdos usuários de língua de sinais, assumidas na educação bilíngue. Concluíram que a escrita dos sinais constitui-se como ferramenta eficiente para maximizar o desenvolvimento das funções psicológicas superiores dos aprendizes surdos.

Martins e Oliveira (2015) apresentaram os resultados de pesquisa realizada com alunos surdos do ensino fundamental $\mathrm{I}\left(1^{\mathrm{o}}\right.$ ao $5^{\mathrm{o}}$ ano), de uma escola municipal no interior de São Paulo, com o objetivo de refletir aspectos tradutórios da literatura surda que favoreçam a interação e o interesse de alunos surdos dos anos iniciais e ajudar a refletir a importância da visualidade e o tipo de tradução específica que se precisa para as atividades com crianças surdas.

O artigo de Martins, Albres e Souza (2015) problematizou a proposta bilíngue para crianças surdas na Educação Infantil e sua importância para o desenvolvimento linguístico do surdo. Enfatizaram a necessidade de políticas que estimulem a entrada da criança surda neste nível de ensino e valorizem a especificidade da surdez numa vertente bilíngue (Libras/português). 
Em relação à dissertação abordada nesse eixo, Ferreira (2015) investigou como determinados conceitos científicos são desenvolvidos pelo professor em aulas de ciências naturais, considerando-se as necessidades educacionais dos alunos com surdez. Seu estudo apontou para a necessidade de alterações no atual paradigma da educação de surdos no Brasil.

Quanto aos TCC considerados nesse eixo: Campos (2009) observou uma escola especial destinada ao atendimento de crianças surdas, com o intuito de verificar se há um destaque para o aspecto visual do aprendizado mediado pela Língua de Sinais, e se existe uma proposta de educação bilíngue. Verificou que há o uso da Libras em todos os momentos (pedagógicos e lúdicos), mas a fala também é estimulada constantemente, principalmente nos momentos de leitura individual e em grupo. Sacconi (2014) realizou uma pesquisa etnográfica com observação de campo numa sala de Ensino Fundamental I, situada em escola municipal Pólo Bilíngue Libras - Português. A pesquisa buscou encontrar as especificidades da educação de surdos em ambiente bilíngue, os métodos de ensino e como ocorrem as trocas de experiências em língua de sinais. O trabalho considerou a sala bilíngue como um espaço privilegiado para a aprendizagem escolar dos alunos surdos e para as trocas de experiências em Língua de Sinais.

Cruz (2015) analisou as possibilidades de relação entre professor ouvinte e aluno surdo. Após análise, concluiu que há diversas barreiras no processo de formação desses alunos e dificuldades em estabelecer uma relação satisfatória professor ouvinte e aluno surdo. Piccolo (2015) procurou entender como é a inclusão de um aluno surdo em uma escola regular e concluiu que as escolas ainda não estão preparadas para atender ao aluno surdo, uma vez que faltam profissionais, materiais especializados e uma compreensão sobre as necessidades e peculiaridades deste aluno. Possidente (2015) verificou a inserção da criança surda na escola regular e concluiu que a educação dessa criança ainda é submetida à lógica ouvinte e os sentimentos e desejos da criança surda, que é o principal sujeito deste processo de "inclusão", nem sempre são levados em consideração.

A leitura das produções científicas que constituíram esse eixo permitiu verificar diferentes enfoques. Foi possível constatar uma preocupação com as práticas educativas para crianças surdas, tais como, a utilização da Libras desde a educação infantil e as experiências de alunos surdos em salas bilíngues. É consenso entre a maioria dos pesquisadores que a educação bilíngue tem um papel decisivo na educação dos alunos surdos. A esse respeito, Lodi e Lacerda (2009) afirmam que a proposta bilíngue surge 
da necessidade de um desenvolvimento satisfatório de linguagem para a constituição dos sujeitos e enfatizam a necessidade de que o surdo adquira o mais precocemente possível a língua de sinais, considerada como primeira língua e, como segunda, aquela utilizada por seus pais.

Outro aspecto citado refere-se a inserção de alunos surdos na educação básica sem a compreensão sobre as necessidades e peculiaridades deste aluno. As produções de Guarinello (2006), Campos (2009) e Angelucci; Luz (2010) trazem diferentes olhares sobre a educação dos surdos, tais como: o intérprete como recurso suficiente ou não para o aluno surdo aprender; a utilização da oralidade e outros métodos que estimulem a fala. Para esses autores não há, ainda, nas redes de ensino, um consenso a respeito da efetividade da educação bilíngue para as crianças surdas.

Sobre essa questão, Louzada, Martins e Giroto (2017) reforçam que qualquer ação adversa a esse movimento pode representar um retrocesso aos direitos linguísticos dos surdos merecidamente reconhecidos e conquistados.

Por sua vez, ao relacionarem a necessidade de utilização de metodologias visuais no ensino de alunos surdos com a falta de preparo docente, Giroto, Pinho e Martins (2016) mencionam que as crianças e jovens surdos se sentem prejudicados pela baixa efetividade do sistema educacional, no que se refere à garantia da aprendizagem, aliada à ineficiência da formação docente.

O eixo "Repercussões da educação bilíngue no âmbito das políticas públicas educacionais" compreendeu quatro artigos publicados na base de dados SciELO, três trabalhos de conclusão de curso e um relatório localizados na biblioteca digital da Unicamp.

Quanto aos artigos vinculados a esse eixo, Lacerda, Albres e Drago (2013) analisaram a atual política para educação de alunos com surdez no município de São Paulo. Ressaltaram que é preciso acompanhar os efeitos da implementação das legislações a fim de compreender seus impactos sobre as práticas educacionais que envolvem alunos surdos. Fernandes e Moreira (2014), que avaliaram a viabilidade das estratégias adotadas nos textos que sistematizam a política nacional de educação especial e inclusiva. Campello e Rezende (2014), que apresentaram a trajetória histórica do Movimento Surdo em defesa das Escolas Bilíngues para Surdos, ao longo dos últimos anos, quando da iminente ameaça de fechamento da escola centenária, o Instituto Nacional de Educação de Surdos, em 2011. Por fim, Nunes et al. (2015) debateram questões que envolvem a educação inclusiva e a escola bilíngue para surdos. 
Concluíram que seria um caminho se as políticas públicas valorizassem a Libras tanto nos espaços escolares como nos demais espaços sociais para que o surdo não tivesse o acesso apenas na escola.

Os TCC relacionados nesse eixo compreenderam os estudos de Bonaccorsi (2008), que realizou um levantamento bibliográfico das leis, e decretos vigentes, do discurso de professores e alunos sobre a inclusão. Concluiu que o cenário da inclusão nas escolas brasileiras ainda está longe do discurso encontrado nas leis. Bueno (2009) discutiu se as práticas inclusivas têm contemplado as demandas educacionais específicas do aluno surdo, para que a inclusão ocorra de fato, como pretendem as políticas públicas atuais. Após análise, não considerou que a inclusão social do surdo seja uma questão espacial (escola regular versus escola especial), mas sim de língua, métodos, formação de professores. Machado (2013) analisou a evolução da Legislação Federal em relação à formação de professores para a educação dos surdos na escola e a contribuição da Faculdade de Educação (FE) e da UNICAMP no sentido de contemplar a Lei 5.626/05. A conclusão a que se chegou é que tanto a FE como a UNICAMP contribuíram pouco para o cumprimento do Decreto 5626/05 e, portanto, para a formação de educadores.

Nesse eixo também foi incluído o relatório produzido por um Grupo de Trabalho do Ministério da Educação, designado pelas Portarias nº1.060/2013 e nº1/2013 (BRASIL, 2014), criado para traçar metas e recomendações para a realização da Política Linguística de Educação Bilíngue. Esse relatório enfatizou a desvinculação da educação linguística de surdos da educação especial.

Foi possível perceber, no que tange às publicações elencadas nesse eixo, apontamentos sobre as dificuldades na implementação das leis, bem como divergências entre o que está escrito na lei e o que é praticado. Além de reflexões acerca da não garantia do direito à Libras e de classe e/ou escolas bilíngue para surdos. Para Lodi (2013) essa questão apenas reitera a dissonância entre os discursos políticos oficiais sobre os modos de organização da educação para os surdos, na Política Nacional de Educação Especial na Perspectiva da Educação Inclusiva (BRASIL, 2008) e no Decreto n. 5.626/2005 (BRASIL, 2005).

\section{Considerações finais}


A partir desse levantamento bibliográfico sistematizado foi possível identificar que nem todas publicações ressaltaram as implicações da Política Nacional de Educação Especial na Perspectiva da Educação Inclusiva (BRASIL, 2008), da lei $\mathrm{n}^{\circ} 10.436$ (BRASIL, 2002) para a educação de surdos em contraposição às normativas presentes no Decreto nº 5.626/05 (BRASIL, 2005).

Embora essas leis (BRASIL, 2002; 2005; 2008) tenham motivado estudos sobre essa temática, ainda aparecem nas publicações diferentes concepções sobre a educação dos surdos, tais como: apenas a presença do intérprete em sala de aula é suficiente para garantir a inclusão do aluno surdo; a utilização de metodologias orais; os professores não relacionarem as suas dificuldades de ensinar com as dificuldades dos alunos surdos em aprender. Assim como foram identificadas publicações que também destacaram a proposta bilíngue como uma realidade possível e os benefícios, quando utilizada na educação infantil e nas séries iniciais do ensino fundamental, principalmente no que diz respeito à apropriação da Libras e à constituição do sujeito surdo por meio dessa língua de instrução.

Ao abordarem os fatores que podem influenciar o processo de inclusão dos surdos, as publicações citaram o despreparo dos professores para atuação com alunos surdos na perspectiva bilíngue, apenas parte dessa produção científica revelou as contradições presentes nas políticas e dispositivos legais que tratam, direta ou indiretamente, da educação de surdos.

Os estudos empreendidos exploraram diferentes aspectos da formação e atuação do professor com surdos. No entanto, a escassez de produções que, pontualmente, abordem essa problemática na educação infantil e séries iniciais do ensino fundamental caracteriza a incipiente educação bilíngue vigente no país para o alunado matriculado nessas etapas educacionais, ao se considerar o atual contexto. As publicações indiciam como está a formação do professor para atuação na educação bilíngue de surdos, quais as readequações na grade dos cursos de formação são necessárias, os benefícios da Libras introduzida desde a educação infantil e os profissionais necessários. A questão que fica é: por que a mudança não ocorre de fato?

Ficou evidente que a atual formação do professor não oferece os subsídios necessários para atuação no contexto educacional bilíngue, por conseguinte num contexto inclusivo. O que parece estar faltando é a correlação entre a realidade vivida por alunos surdos em sala de aula com a atual formação do professor. É preciso superar 
as pressões políticas e linguísticas para que se dê lugar a uma política inclusiva concreta.

\section{REFERENCIAS}

ANGELUCCI, C. B.; LUZ, R. D. Contribuições da escola para a (de) formação dos sujeitos surdos. Revista Semestral da Associação Brasileira de Psicologia Escolar e Educacional, v. 14, n. 1, p. 35-44, jan./jun., 2010.

BONACORSI, M. As políticas inclusivas no campo da surdez: a lei que ampara e a prática que se cumpre. 2008. 75f. Trabalho de conclusão de curso. UNICAMP. Campinas, SP, 2008.

BRASIL. Lei ${ }^{\circ}$ 10.436, de 24 de abril de 2002. Dispõe sobre a Língua Brasileira de sinais-Libras e dá outras providências. Brasília, DF: Diário Oficial da União, 2002. Disponível em: http://www.planalto.gov.br/ccivil_03/leis/2002/110436.htm. Acesso em: 17 mar. 2018.

BRASIL. Decreto $n^{\circ}$ 5.626, de 22 de dezembro de 2005. Regulamenta a Lei $n^{\circ} 10.436$, de 24 de abril de 2002. Dispõe sobre a Língua Brasileira de Sinais - Libras, e o art. 18 da Lei $\mathrm{n}^{\circ}$ 10.098, de 19 de dezembro de 2000. Brasília, DF: Diário Oficial da União, 2005. Disponível em: http://www.planalto.gov.br/ccivil_03/_ato20042006/2005/decreto/d5626.htm. Acesso em: 17 mar. 2018.

BRASIL. Política Nacional de Educação Especial na Perspectiva da Educação Inclusiva. Brasília: MEC, SEESP, 2008. Disponível em:

http://portal.mec.gov.br/seesp/arquivos/pdf/politica.pdf. Acesso em: 17 mar. 2018.

BRASIL. Ministério da Educação. Secretaria de Educação Continuada, Alfabetização, Diversidade e Inclusão. Relatório do Grupo de Trabalho designado pelas Portarias $\mathbf{n}^{\mathbf{0}}$ 1.060/2013 e n⿳ 91/2013. Subsídios para a Política Linguística de Educação Bilíngue - Língua Brasileira de Sinais e Língua Portuguesa - a ser implementada no Brasil, 2014.

BUENO, D. B. Para quem tem olhos de ver e ouvir: os conflitos entre as políticas públicas e as experiências de inclusão de surdos. 2009. 107f. Trabalho de conclusão de curso. UNICAMP. Campinas, SP, 2009.

CAMPELLO, A. R.; REZENDE, P. L. F. Em defesa da escola bilíngue para surdos: a história de lutas do movimento surdo brasileiro. Educ. rev., n. esp-2, p. 71-92, 2014.

CAMPOS, S. M. Aluno surdo em escola especial: reflexões acerca da alfabetização e a importância da Libras neste processo. 2009. 59f. Trabalho de conclusão de curso. UNICAMP. Campinas, SP, 2009.

CRUZ, P. S. da. Relação professor ouvinte e aluno surdo: um olhar sobre a formação inicial do professor. 2015. 59f. Trabalho de conclusão de curso. UNICAMP. Campinas, SP, 2015. 
EYNG, D. B. A inclusão do sujeito surdo no ensino regular do ponto de vista de alunos surdos, familiares, professores e intérpretes. Rev. soc. bras. fonoaudiol. v. 17, n. 3, p. 376, 2012.

FARIA, J. G. Formação, profissionalização e valorização do professor surdo: reflexões a partir do Decreto 5.626/2005. Rev. bras. educ. espec., v. 17, n. 1, p.87-100, 2011.

FERNANDES, E. Linguagem e surdez. Porto Alegre: Artmed, 2003.

FERNANDES, S.; MOREIRA, L. C. Políticas de educação bilíngue para surdos: o contexto brasileiro. Educ. rev., n. esp-2, p. 51-69, 2014.

FERREIRA, A.B. O processo de escolarização de crianças surdas no ensino fundamental: um olhar para o ensino de ciências articulado aos fundamentos da astronomia. p. 127. Dissertação (Mestrado em Educação). Universidade Estadual Paulista "Júlio de Mesquita Filho". Bauru, 2015.

FRANCO, M. Educação superior bilíngue para surdos: o sentido da política inclusiva como espaço da liberdade: primeiras aproximações. Rev. bras. educ. espec., v. 15, n. 1, p.15-30, 2009.

GIROTO, C. R. M.; BERBERIAN, A. P.; SANTANA, A. P. Saúde, Educação e Educação Especial: princípios e paradigmas norteadores das práticas em saúde no contexto educacional inclusivo. In: C. R. M. Giroto. (Org.). Serviços de apoio em Educação Especial: um olhar para diferentes realidades. Alcalá de Henares: Servicio de Publicaciones de la UAH, 2014, p. 101-24.

GIROTO, C. R. M.; MARTINS, S. E. S. O.; LIMA, J. M. R. Formação de professores e inserção da disciplina Libras no Ensino Superior: perspectivas atuais. Revista IberoAmericana de Estudos em Educação, v. 2, p. 741-758, 2015.

GIROTO, C. R. M.; PINHO, G. G.; MARTINS, S. E. S. O. A disciplina de Libras na pedagogia: em análise a formação do formador. In: POKER, R. B.; MARTINS, S. E. S. O.; GIROTO, C. R. M. (Org.). Educação inclusiva: em foco a formação de professores. 1ed.São Paulo: Cultura Acadêmica, v. 1, p. 153-172, 2016.

GUARINELLO, A. C. A inserção do aluno surdo no ensino regular: visão de um grupo de professores do Estado do Paraná. Rev. bras. educ. espec., v.12, n. 3, p. 317-330, 2006.

LACERDA, C. B. F.; ALBRES, N. A.; DRAGO, S. L. S. Política para uma educação bilíngue e inclusiva a alunos surdos no município de São Paulo. Educação e Pesquisa, v. 39, p. $65,2013$.

LODI, A. C. B.; LACERDA, C. B. F. A inclusão escolar bilíngue de alunos surdos no ensino infantil e fundamental: princípios, breve histórico e perspectivas. In: LACERDA, C.B.F, LODI, A.C.B. (org.). Uma escola duas línguas: letramento em língua portuguesa e língua de sinais nas etapas iniciais de escolarização. Porto Alegre: Editora Mediação, 2009. p. 7-32. 
LODI, A. C. B. Educação bilíngue para surdos e inclusão segundo a Política Nacional de Educação Especial e o Decreto n. 5.626/05. Educação e Pesquisa. São Paulo, v. 39, n. 1, p. 49-63, 2013. Disponível em:

http://www.scielo.br/scielo.php?script=sci_arttext\&pid=S1517-97022013000100004. Acesso em: 11 out. 2018.

LODI, A. C. B; BORTOLOTTI, E. C.; CAVALMORETI, M. J. Z. Letramentos de surdos: práticas sociais de linguagem entre duas línguas/culturas. Bakhtiniana, São Paulo, v. 9, n. 2, p. 131-149, ago./dez., 2014.

LOUZADA, J. C. A.; MARTINS, S. E. S. O.; GIROTO, C. R. M. A disciplina Libras na formação de professores: desafios para a formulação de espaços educacionais bilíngues. Práxis Educativa, v. 12, p. 864-886, 2017.

\section{MACHADO, J. E. Formação de Professores em Libras para a inclusão dos surdos} na escola: a contribuição do curso de pedagogia e da Universidade Estadual de Campinas. 2013. 137F. Trabalho de conclusão de curso. UNICAMP. Campinas, SP, 2013.

MARQUES, H. de C. R.; BARROCO, S. M. S.; SILVA, T. dos S. A. O Ensino da Língua Brasileira de Sinais na Educação Infantil para Crianças Ouvintes e Surdas: Considerações com Base na Psicologia Histórico-Cultural. Rev. Bras. Ed. Esp., v. 19, n. 4, p. 503-518, out./dez., 2013.

MARTINS, V. R. O.; OLIVEIRA, G. S. Literatura surda e ensino fundamental: resgates culturais a partir de um modelo tradutório com especificidades visuais. Educ. Soc., 2015, v. 36, n. 133, p. 1041-1058.

MARTINS, V. R. de O.; ALBRES, N. de A.; SOUSA, W. P. A. Contribuições da Educação Infantil e do brincar na aquisição de linguagem por crianças surdas. ProPosições, v. 26, n. 3, p. 103-124, set./dez., 2015.

NASCIMENTO, S. P. F.; COSTA, M. R. Movimentos surdos e os fundamentos e metas da escola bilíngue de surdos: contribuições ao debate institucional. Educ. rev., n. esp-2, p. 159-178, 2014.

NUNES, S. S. N. et al. Surdez e educação: escolas inclusivas e/ou bilíngues? Revista Quadrimestral da Associação Brasileira de Psicologia Escolar e Educacional, v. 19, n. 3, p. 537-545, set./dez., 2015.

PEIXOTO, R. C. Algumas considerações sobre a interface entre a Língua Brasileira de Sinais (Libras) e a Língua Portuguesa na construção inicial da escrita pela criança surda. Cad. CEDES, v. 26, n. 69, p. 205-229, 2006.

PICCOLO, L. G. A inclusão de uma aluna surda no ensino fundamental: estudo de caso. 2015. 80f. Trabalho de conclusão de curso. UNICAMP. Campinas, SP, 2015.

PORTIOLI, V. P. A inclusão de alunos surdos e a formação do professor: estudo de caso. 2006. 71f. Trabalho de conclusão de curso. UNICAMP. Campinas, SP, 2006. 
POSSIDENTE, M. A. C. A criança surda na educação infantil e a produção de cultura no processo de inclusão: o que muda ou cala? 2014. 160f. Trabalho de conclusão de curso. UNICAMP. Campinas, SP, 2014.

QUADROS, R. M.; LILO-MARTIN, D; PICHLER, D. C. Sobreposição no desenvolvimento bilíngue bimodal. RBLA, Belo Horizonte, v. 14, n. 4, p. 799-834, 2014.

SACCONI, G. C. Sala bilíngue para surdos: métodos e relações interpessoais. 2014. 58f. Trabalho de conclusão de curso. UNICAMP. Campinas, SP, 2014.

SILVA, T. S. A.; BOLSANELLO, M. A. Atribuição de significado à escrita, por crianças surdas usuárias de língua de sinais. Educ. rev., n. esp-2, p. 129-142, 2014.

SILVA, N. L. Professores surdos e professores de surdos, uma formação impossível. 2015. 70f. Trabalho de conclusão de curso. UNICAMP. Campinas, SP, 2015.

SOARES, R. S. Educação bilíngue de surdos: desafios para a formação de professores - Tese de doutorado. USP. São Paulo - SP, 2013.

SOUZA, S. M. Apontamentos sobre a formação de professores bilíngues para educação de surdos em língua de sinais - Dissertação de Mestrado. Campinas, SP. 2012.

STREIECHEN, E. M.; KRAUSE-LEMKE, C. Análise da produção escrita de surdos alfabetizados com proposta bilíngue: implicações para a prática pedagógica. In: RBLA, Belo Horizonte, v. 14, n. 4, p. 957-986, 2014.

\section{Como referenciar este artigo}

CICILINO, J. E. M.; GIROTO, C. R. M.; VITTA, F. C. F. Formação de Professores para a educação bilíngue de surdos na educação infantil e séries iniciais do ensino fundamental. Revista on line de Política e Gestão Educacional, Araraquara, v. 22, n. esp. 2, p. 794-809, dez., 2018. ISSN: 1519-9029. DOI: 10.22633/rpge.unesp.v22.nesp2.dez.2018.11913

Submetido em: 10/08/2018

Aprovado em: 30/09/2018 